\title{
A política da voz e do dizer segundo Adriana Cavarero
}

Thiago Dias ${ }^{1}$

\begin{abstract}
Resumo: Um dos objetivos deste artigo é apresentar a relação entre política e palavra proposta por Adriana Cavarero em "Vozes plurais". Sob influência declarada de Hannah Arendt, Cavarero coloca a singularidade no centro de seu pensamento, e o segundo objetivo deste artigo é mostrar que a singularidade é uma ideia chave para a crítica do patriarcado. Uma análise fina de Platão e Aristóteles mostra que eles dividiram o logos em um aspecto sonoro e um aspecto lógico e, ato contínuo, soterraram a voz sob o semântico estabelecendo uma hierarquia que marcaria toda a tradição. A diferença de gênero se uniria a esta hierarquia, pois a tradição atribuiria a voz à mulher e o semântico ao homem. Carnal, sensual e particular, a voz e a mulher se mantiveram à sombra do espiritual, racional e universal garantidos pelo homem e seu logos sem voz. Em um passo adicional, Cavarero apresenta uma fenomenologia vocálica da unicidade a fim de mostrar que a voz porta a singularidade humana. Diante disto, faz-se necessário reconduzir a palavra à sua raiz vocálica, especificamente acústica e tradicionalmente feminina, a fim de elaborar uma política pós-patriarcal.
\end{abstract}

Palavras-chave: Cavarero - Arendt - Feminismo - Singularidade - Voz

\section{The politics of the voice and of saying in Adriana Cavarero}

\begin{abstract}
One of the purposes of this article is to present the link between politics and speech proposed by Adriana Cavarero in "For More Than One Voice". Under declared influence of Hannah Arendt, Cavarero places uniqueness at the center of her thought, and the second purpose of this article is to show that uniqueness is a key idea for the fight against patriarchy. A fine analysis of Plato and Aristotle shows that they split logos into both, a sound and a logical aspect, and buried voice under semantics; this movement established a hierarchy that would mark the whole tradition. Gender difference is placed under this hierarchy, since tradition would attribute voice to woman and semantics to man. Fleshy, sensual and particular, voice and woman remained in the shadow of the spiritual, rational and universal guaranteed by man and his voiceless logos. Going one step further, Cavarero presents a vocal phenomenology of uniqueness in order to show that the voice carries human uniqueness. It is then necessary to bring speech back to its vocal root, which is specifically acoustic and traditionally feminine, in order to elaborate a post-patriarchal policy.
\end{abstract}

Keywords: Cavarero - Arendt - Feminism - Uniqueness - Voice

\footnotetext{
${ }^{1}$ Doutor em filosofia pela Universidade de São Paulo. Além de tradutor, é coordenador do grupo de estudos "Violência em tempos sombrios" do NEV-USP e foi pesquisador visitante na Freie Universität Berlin em 2015. Contato: thdiass@yahoo.com.br
} 


\section{Introdução}

Este texto tem duas pretensões: uma bastante modesta e outra um tanto mais ousada. A primeira é simplesmente apresentar um elemento do pensamento político de Adriana Cavarero. Esta apresentação, evidentemente, está direcionada ao tema do evento que deu origem a este dossiê, ou seja, pretendo mostrar um vínculo entre política e feminismo no pensamento de Cavarero. Meu segundo interesse, um pouco mais ambicioso, é mostrar como certa leitura da obra de Hannah Arendt, leitura que apresentei em minha tese de doutorado ${ }^{2}$, se aproxima com o pensamento de Cavarero, sobretudo ao atribuir à singularidade um papel particularmente importante na desmontagem da tradição de filosofia política. Para não desviar do tema do dossiê, deixei em segundo plano o debate com especialistas do pensamento arendtiano.

Apesar de Cavarero já ser pensadora bastante conhecida na Europa e nos EUA, ainda é preciso apresentá-la para o público brasileiro. Ela é professora de filosofia política na Universidade de Verona, na Itália. Sua formação se deu na Universidade de Pádova, onde se dedicou fundamentalmente aos estudos antigos, em especial a Platão. Além disto, e mais importante aqui, Cavarero participou intensamente, em teoria e na prática, do movimento feminista italiano. Foi uma das fundadoras do Diótima, uma comunidade filosófica feminina criada em 1983 sob o lema: ser mulher e pensar filosoficamente. ${ }^{3}$ É desta época seu "Per una teoria della differenz̧a sessuale" [Por uma teoria da diferença sexual], publicado em um volume coletivo organizado pela Diótima e tido como uma espécie de manifesto filosófico do feminismo italiano. Outro aspecto da trajetória de Cavarero relevante aqui é seu declarado débito intelectual com Hannah Arendt, débito que a animou a fundar, em 2016, o Centro de Estudos Politicos Hannah Arendt na Universidade de Verona. No Brasil, a revista Estudos feministas, da UFSC, publicou seu diálogo com Judith Butler a respeito da condição humana ${ }^{4}$, e, salvo engano, seu único livro traduzido para o português é Vozes plurais ${ }^{5}$, publicado originalmente em 2005.

Parte considerável do pensamento feminista tem como procedimento usual certo retorno ao passado a fim de rever a posição ocupada pelas mulheres ao longo dos séculos. Cavarero está entre os que procedem desta forma, mas, de modo mais específico, ela o faz de maneira a se aproximar daqueles que se dedicaram a desconstruir, ou a desmontar a tradição da filosofia ocidental. Influenciados pelas críticas nietzscheanas a Platão e pela destruição da metafísica proposta por Heidegger, inúmeros pensadores, vinculados ou não ao feminismo, se lançaram à hercúlea tarefa de, não apenas criar novas filosofias, mas refundar o pensamento ocidental sobre novas bases.

É importante assinalar que desmontar a tradição não equivale, em absoluto, a recusar o passado. De fato, o olhar direcionado à tradição é fundamentalmente crítico e pretende, inequivocamente, corrigir problemas profundos que marcam a cultura de modo decisivo. Mas isto não se confunde com o puro e simples cancelamento do passado, com a mera recusa

\footnotetext{
${ }^{2}$ Cf. DIAS, Totalitarismo, tempo e ação: uma interpretação de A condição humana de Hannah Arendt.

3 A comunidade ainda está ativa e mantém um site: http://www.diotimafilosofe.it/presentazione/ Há uma apresentação cuidadosa da comunidade em MENDES, "Diótima e a construção da legitimidade do pensamento da diferença sexual no espaço público".

${ }^{4}$ Cf. CAVARERO, BUTLER, "Condição humana contra 'natureza"”.

${ }^{5}$ Cf. CAVARERO, A. Vozes plurais: filosofia da expressão vocal. Belo Horizonte: Editora UFMG, 2011.
} 
dos grandes autores ou das grandes ideias. Desmontar a tradição é algo muito distinto de fazer tábula rasa do passado imaginando ser possível simplesmente inventar o futuro ex-nibilo, ou a partir da pura vontade de recusar a tradição.

Apesar das muitas diferenças entre os pensadores que compõem esta linhagem, é possível notar que é comum a muitos deles este retorno às origens intelectuais do ocidente em busca de certos arranjos que marcaram a tradição. Uma vez identificados, estes arranjos fundamentais são cuidadosamente analisados e, com isto, têm seus pressupostos e seus valores desvendados. Desta revelação, decorre a possibilidade de desfazer estes nós que sustentaram milênios de filosofia e, assim, abrir novos horizontes de pensamento. Pertencem a esta linhagem, aqui definida de modo meramente indicativo, Derrida, Jaspers, Lévinas, Merleau-Ponty e outros tantos, dentre os quais Hannah Arendt e Adriana Cavarero.

Arendt volta às origens em sua luta contra o totalitarismo, uma luta que não se resume à discussão das formas políticas, pois exige também o questionamento e a desmontagem da filosofia política. Como veremos mais à frente, a análise arendtiana encontra na origem uma hostilidade fundamental entre filosofia e política, uma hostilidade que conduziu a filosofia a pensar contra a política mesmo quando se imaginava pensando a política. Segundo Arendt, a condenação de Sócrates pela cidade é o impulso fundamental da filosofia política de Platão, que assim introduziu na fundação da tradição esta hostilidade da filosofia contra a política.

Em Vozes plurais, Cavarero também retorna às origens, mas preocupada com as questões feministas, o que a leva a encontrar uma série de mulheres silenciadas a partir de certa interpretação do que é o logos. No caso de Cavarero, a tradição a ser desmontada recebe o nome de ordem simbólica patriarcal, uma estrutura "notoriamente dicotômica, que concebe o homem como mente e a mulher como corpo, [dentro da qual] a cisão do logos em pura phoné feminina e em puro semantikon masculino resulta coerente com o sistema e o confirma" ${ }^{\text {. }} \mathrm{Na}$ análise de Cavarero, o silenciamento das mulheres não é apenas um fenômeno político, mas é também um traço fundamental da filosofia, o que exige o procedimento de ir às origens para desmontar o que lá se estabeleceu.

A proximidade no procedimento, no entanto, não é suficiente para afirmar o débito de Cavarero com Arendt, pois vários autores voltaram às origens de maneira parecida - 0 apêndice de Vozes plurais se chama "Dedicado a Derrida" e "quer ser antes de tudo uma dedicação: um reconhecimento e uma crítica expressamente dedicados a Derrida" " O ponto de união mais interessante entre Cavarero a Arendt é a centralidade conferida por ambas à singularidade (e aqui me filio a Cavarero como leitora de Arendt). Apesar das enormes diferenças quanto ao motivo de Arendt e Cavarero se lançarem ao passado - Arendt luta contra o totalitarismo; Cavarero, contra o patriarcado - ambas se encontram na afirmação da singularidade como ideia chave para fazer frente à tradição.

\section{A questão Arendt no feminismo}

Antes de vermos isto com mais cuidado, faz necessário um pequeno excurso, pois a aproximação entre Arendt e o feminismo impõe tratarmos, ainda que brevemente, da

\footnotetext{
${ }^{6}$ CAVARERO, Vozes plurais, p. 132.
}

${ }^{7}$ CAVARERO, Vozes plurais, p. 268. 
“questão Arendt no feminismo". Isto porque a relação entre Arendt e o feminismo é composta por um pequeno entrave inicial que, embora já tenha sido superado pelos estudos arendtianos, ainda deve ser comentado fora dos círculos muito especializados.

Hannah Arendt não era feminista. Mais do que isto, mostrou reservas contra o movimento nas poucas vezes em que tratou do assunto. Uma das ocasiões é a conhecida entrevista concedida a Gunter Gauss, em 1964:

Gauss: Compreendo. Voltemos agora, por gentileza, à questão da emancipação [das mulheres]. Isto tem sido uma questão para você?

Arendt: Sim, naturalmente, sempre houve o problema enquanto tal. Eu efetivamente sou mais à moda antiga. Sempre achei que há determinadas ocupações que são inadequadas para mulheres, que não lhes caem bem, se posso colocar desta forma. Não parece bom quando uma mulher dá ordens. Caso queira manter sua qualidade feminina, ela deve tentar não estar em situações como estas. Se estou certa ou não, eu não sei. Eu mesma sempre vivi de acordo com isto de maneira mais ou menos inconsciente - ou melhor, de maneira mais ou menos consciente. O problema para mim, pessoalmente, não teve papel nenhum. Veja, eu simplesmente fiz o que eu queria fazer. ${ }^{8}$

O silêncio de Arendt a respeito do feminismo associado a algumas poucas passagens como esta costumam causar decepção em leitores, sobretudo em leitoras, que chegam à obra de Arendt como quem chega aos feitos de uma grande heroína feminista. Se adotarmos esta perspectiva, ou seja, se procurarmos por alguém que defende diretamente a emancipação feminina, talvez a vida de Arendt seja digna do status de heroína, mas sua obra certamente não é. Como escreve Bonnie Honig, em um texto publicado há mais de vinte anos, "Nos anos 1970 e no início dos anos 1980, feministas se voltaram a Arendt como pensadora mulher com a expectativa de que ela teria algo especificamente ginecocêntrico a lhes oferecer. (E, de fato, algumas ainda o fazem) Muitos comentadores voltaram desapontados".

Com o passar do tempo, no entanto, e felizmente, a "questão da mulher em Arendt" aos poucos se converteu na "questão Arendt no feminismo" ", pois o pensamento feminista deixou de centralizar o fato de Arendt ser mulher e ter a "experiência" feminina, e passou a se ocupar dos possíveis recursos que o pensamento político arendtiano pode oferecer ao pensamento feminista. Feita esta mudança fundamental de perspectiva, o pensamento de Arendt ganha interesse em muitos sentidos, como prova o frequente recurso de pensadoras feministas como Seyla Benhabib, Bonnie Honig, Judith Butler e Cavarero à obra de Arendt. A variedade da abordagem de cada uma destas pensadoras sobre a obra arendtiana demonstra a potência deste pensamento, que pode oferecer múltiplas perspectivas para vários

\footnotetext{
8 O vídeo da entrevista é facilmente encontrado na internet, e o Centro Arendt da Universidade de Verona publicou em seu site tanto o vídeo quanto a transcrição da entrevista. A tradução acima foi feita com base nesta transcrição, a única a que tive acesso durante a quarentena (http://www.arendtcenter.it/en/tag/gunter-gaus/ — acessado em 24.03.2020). No Brasil, a entrevista foi publicada na coletânea Compreender: formação, exílio, totalitarismo (São Paulo: Cia das Letras, 2008) sob o título "Só permanece a língua materna".

${ }^{9}$ HONIG, "Introduction: The Arendt Question in Feminism", p. 2.

${ }^{10}$ Eu tomo esta oposição de Honig, que por sua vez a tomou de Sandra Harding, Op. Cit., p. 3.
} 
problemas políticos, dentre os quais o feminismo. Portanto, é como pensadora política, não como mulher ou como pensadora feminista, que Arendt inspira o feminismo.

\section{Arendt e a tradição política}

O que impulsiona Arendt à tarefa de desmontar a tradição é o evento totalitário, ou seja, os regimes de Hitler e de Stálin. O totalitarismo, para Arendt, tem origens históricas, sociais, econômicas, políticas, culturais e também filosóficas. Muito lamentavelmente, as origens filosóficas não se resumem à pseudociência de Hitler ou ao darwinismo de segunda categoria, mas podem ser encontradas nos grandes autores do passado. Arendt faz parte da geração de alemães cultos e orgulhosos de sua Kultur que tiveram que repensar esta cultura depois de Auschwitz. À sua maneira, e seguindo sua formação, feita no movimento fenomenológico, ela vai às origens do pensamento filosófico a fim de encontrar quais elementos da tradição que tiveram algum papel no totalitarismo. Isto não quer dizer, em absoluto, que Platão e Aristóteles sejam a causa do totalitarismo, mas quer dizer que certos arranjos filosóficos que sustentaram a tradição de filosofia política participaram daquilo que não deveria ter acontecido, do que decorre a exigência ética de desmontar estes arranjos.

Em sua análise das origens da tradição de filosofia política, Arendt encontra em Platão o surgimento de uma hostilidade mútua entre a filosofia e a política. Esta hostilidade é um problema, pois coloca filosofia e política em conflito, mas não as desvincula completamente, ou seja, filosofia e política se procuram mutuamente, mas se entendem mal por trabalharem de modos fundamentalmente incompatível. A alegoria da caverna é um momento particularmente ilustrativo do surgimento desta hostilidade. $\mathrm{Na}$ alegoria, lembremos, o âmbito das relações humanas, ou seja, o âmbito em que a política e a vita activa acontecem, é descrito como o fundo da caverna, lugar onde o sol não chega, lugar próprio para sombras, para erro e para o que não é. No âmbito das relações humanas, proliferam o engano e a confusão, a verdade não tem papel e nada de fixo ou estável pode se estabelecer. Em oposição a este lugar desprezível, há o lado de fora da caverna, espaço marcado pela luz, pela verdade e pelo que é. Ali, onde acontece a filosofia, onde a vita contemplativa tem lugar, encontram-se a verdade e o mundo das ideias fixas, eternas, claras, distintas, cuja visão marca definitivamente o filósofo.

Há um fragmento de Pascal que Arendt costuma citar para resumir esta oposição e evidenciar a avaliação tradicional sobre ela:

Em geral, só imaginamos Platão e Aristóteles com grandes túnicas de pedantes. Eram pessoas honestas e, como as outras, rindo com seus amigos; e, quando se divertiam em fazer suas Leis e sua Política, fizeram-na brincando. Era a parte menos filosófica e menos séria de sua vida. A mais filosófica consistia em viver simples e tranquilamente. Se escreveram sobre política foi para pôr em ordem um hospício; e, se fizeram menção de falar dela como de uma grande coisa, é que sabiam que os loucos a quem falavam julgavam ser reis e imperadores; entravam nos seus princípios para moderar a loucura deles na medida do possível. ${ }^{11}$

${ }^{11}$ Pascal, Pensamentos, fragmento 331 (numeração Brunschvicg) em tradução de Sérgio Milliet. 
Com a alegoria, Platão estabelece uma distinção fundamental entre os dois âmbitos e não há mais como estimar ou prezar aquele hospício que é o âmbito das relações humanas. Feita esta separação entre um âmbito superior e outro inferior, cabe ao filósofo, portanto, ordenar aquela loucura toda de acordo com as formas às quais apenas ele teve acesso. Ora, mas os habitantes da caverna não são mera massa passiva pronta para receber a iluminação filosófica. E no momento em que recebem o filósofo, devolvem-lhe a mesma hostilidade alegando que ele faz mal à cidade por suas ideias extravagantes, baseadas nas coisas inexistentes que ele afirma ter visto. Sócrates pagou esta hostilidade com a vida.

Segundo Arendt, esta oposição nascida com Platão marca toda a filosofia política. Todos os demais filósofos políticos que surgiram na tradição ocidental, malgrado as diferenças entre eles, mantiveram intacta a hostilidade e a hierarquia entre filosofia e política. Alguns autores, como Maquiavel, Montesquieu e Tocqueville, não partilharam desta oposição, e por isto mesmo não foram filósofos, mas pensadores políticos. A diferença fundamental aqui está em que estes procuram o que há de específico às relações humanas sem as considerarem como sombras, loucura, erro; ou seja, eles olham para a política sem ter como referência as ideias eternas.

Tanto a oposição entre filosofia e política quanto o desprezo contra a política estão na base dos procedimentos filosóficos mais essenciais, como o esforço para definir "O Homem" ou "A Humanidade" e, em seguida, fundamentar uma filosofia política sobre esta definição. ${ }^{12}$ Todo esforço da filosofia política - e isto, segundo Arendt, jamais foi seriamente questionado - está em encontrar uma definição de Homem que seja capaz de submeter tais ou tais eventos a alguma forma universal de governo ou de história, uma definição que seja capaz de postular uma forma de governo que seja definitiva.

Contra este traço estruturante da tradição de filosofia política, Arendt defende que o pensar político - e não mais a filosofia política — deve encontrar um espaço adequado para a particularidade, mas não uma particularidade que possa ser apreendida por termos gerais como "o indivíduo" ou "a classe". Para elaborar o novo pensar político que a ameaça totalitária exige, faz-se necessário pensar a singularidade do agente, ou seja, pensar adequadamente quem age na esfera pública. A ação política pode ser feita por indivíduos, classes ou grupos, mas, ao afirmar isto, deixamos de lado o peso que está no fato de que determinada ação se deu por aquele indivíduo, classe ou grupo que se encontrava naquela situação inteiramente única e irrepetível. É por conta disto que Arendt elabora uma teoria que define a ação como "a revelação de quem o agente é". A ação política, segundo Arendt, é uma performance em que alguém aparece em público defendendo certos princípios gerais, mas trazendo também sua singularidade à vista de todos. Quem agiu foi aquela pessoa, e sua singularidade é parte da ação.

Como um dos esforços constitutivos da filosofia política é o de desencarnar os agentes particulares a fim de encontrar uma universalidade - como o indivíduo ou a classe —, a proposta de incluir de modo sério, não apenas a particularidade, mas a singularidade de cada agente, equivale a uma ruptura total com a tradição.

${ }^{12}$ Este argumento está desenvolvido tanto em minha tese quanto em DIAS, "Hannah Arendt contra a differentia specifica". 


\section{Cavarero e a desmontagem do patriarcado}

Assim como Arendt, Adriana Cavarero também se vincula à linhagem da desmontagem da tradição e, consequentemente, se lança às origens da cultura Ocidental a fim de identificar alguns arranjos que moldaram a tradição. Assim como Arendt, Cavarero tem a política como preocupação fundamental. E há ainda, por fim, algo que as une mais estreitamente, a saber, o papel da singularidade na tarefa de desmontar a tradição. Diferentemente de Arendt, no entanto, o trabalho de Cavarero conecta esta desmontagem da tradição ao pensamento feminista, do que resulta a possibilidade de vincular de modo estreito, rigoroso e muito profícuo a tradição metafísica e a ordem patriarcal.

Em Vozes plurais, Cavarero se ocupa de modo cuidadoso do tema da voz. Não a vOZ em sentido metafórico, como a opinião expressa ou a posição de determinada parcela da sociedade, mas da voz em seu sentido mais fundamental possível, ou seja, como som resultante do movimento de ar que tem origem nas cavidades carnosas, no corpo profundo, vibra as cordas vocais, passa pela garganta, úvula, palato, língua e sai pela boca para penetrar o ouvido de outro alcançando o tímpano, o martelo, a tuba auditiva e, por fim, as cavidades carnosas deste outro. É este fenômeno que Cavarero analisa.

Mas, por que a voz? O que há de politicamente importante na voz? Mais do que isto, o que há de importante na voz para a tarefa de desmontar a tradição e o patriarcado? Por fim, o que a voz tem a ver com o feminino?

Comecemos com aquilo que Cavarero afirma estar fazendo: segundo ela, o que temos em Vozes plurais é uma fenomenologia vocálica da unicidade. O termo "unicidade" [unicita], pouco comum em português, equivale exatamente à "singularidade" que encontramos no texto de Arendt. A diferença entre os termos se deve a um pequeno movimento de tradução. Em $A$ condição bumana, livro que Arendt escreveu em inglês e depois verteu para o alemão, encontramos os termos uniqueness e Einzigartigkeit. A tradução brasileira, feita a partir do inglês, traduziu uniqueness por "singularidade", o que está correto. A tradução italiana, no entanto, traduziu uniqueness por unicità (este também foi o caminho da tradução francesa, que optou por unicité, e da espanhola, que traz unicidad). Assim, lendo em português, a "unicidade" de Cavarero é exatamente igual à "singularidade" de Arendt.

Em Arendt, como indiquei há pouco, a singularidade é um recurso fundamental para desmontar a tradição, uma vez que a tradição sempre se esforçou para excluir a singularidade em benefício da generalidade. Com "singularidade", Arendt aponta para o caráter único de cada ser humano, ou seja, para aquilo que faz com que cada ser humano seja diferente de qualquer outro ser humano que exista, que tenha existido ou que venha a existir. Usando os termos de Cavarero, aquilo que nos torna únicos é, literalmente, nossa unicidade; e a unicidade é um dos componentes fundamentais da voz que sai da garganta de cada um de nós.

Cada voz "vem certamente de uma pessoa única, inimitável como qualquer pessoa", assegura-nos [Ítalo] Calvino [cujo conto "Um rei à escuta" é analisado nas páginas iniciais]. O escritor atrai a nossa atenção para aquilo que poderíamos chamar uma fenomenologia vocálica da unicidade. Trata-se ao mesmo tempo de uma ontologia que diz respeito à singularidade encarnada de cada 
existência enquanto se manifesta vocalmente. Ontologia e fenomenologia são apenas nomes - demasiadamente técnicos, bem como indulgentes a certo idioleto filosófico - para assinalar como, no registro da voz, ecoa a condição humana da unicidade. ${ }^{13}$

É importante notar que não se trata da noção de indivíduo. Mais do que isto: a singularidade é uma maneira de romper com o conceito de indivíduo, pois, embora ele também aponte para nossa existência como "um", ele aponta sobretudo para algo que partilhamos com todos os humanos. Todos os seres humanos são um indivíduo e isto não singulariza absolutamente ninguém. Eu, Thiago, sou tão indivíduo quanto qualquer leitor deste texto, assim como Hannah, ou Adriana. Para ser capaz de nos tematizar, a filosofia moderna, seguindo a estrutura fundamental da tradição, precisa encontrar em Thiago, Hannah ou Adriana um substrato comum capaz de servir de fundamento, e, para isto, vai até o lado de fora da caverna, de onde volta com a noção de indivíduo, que é capaz de unificar a todos. Do ponto de vista da individualidade — reparem na impropriedade! — Thiago é equivalente a Hannah e Adriana, o que significa que a singularidade foi deixada de lado.

O procedimento é importante, mas não se deve deixar de notar que, além de indivíduo, sou também uma singularidade inteiramente distinta de qualquer outra pessoa que tenha vivido, esteja vivendo ou venha a viver algum dia. Uma manifestação forte desta singularidade está no fato de minha voz ser única, irrepetível e distinta das vozes de qualquer pessoa. A tradição, mesmo quando valorizou a individualidade, expulsou a singularidade e a unicidade dos seres humanos; Arendt e Cavarero recolocam-nas no centro de seu pensamento político e, com isso, contribuem para a desmontagem da tradição.

Cavarero se lança à análise da definição clássica de Homem, ou seja, à definição aristotélica do humano como zoon logon echon, e chama atenção para o fato de que costumamos traduzir esta definição por "animal racional", mas ela literalmente ela quer dizer "vivente que possui logos". Dentro do melhor espírito aristotélico, a definição afirma a existência de um grupo de seres que se classificam como viventes; dentre estes, há os humanos, que se diferenciam por terem logos. Ora, logos vem do verbo legein, que significa "falar", "conectar", "ligar", "recolher". $\mathrm{Na}$ acepção comum, logos é a atividade de quem fala, de quem liga palavras, de quem as conecta umas às outras de maneiras específicas. Ou seja, logos não é apenas emitir som, como fazem os demais animais, mas emitir sons sob determinadas regras. É por isso que na Poética Aristóteles afirma que logos é phoné semantiké; ou seja, logos é voz (phonê), mas é também significado, sentido (semantikề).

Partindo desta definição, portanto, tem-se que os animais e os humanos têm voz, têm phoné. Mas, diferentemente dos humanos, os animais não alcançam a semantiké, de modo que aquilo que realmente distingue os humanos dos demais animais não é o som, mas o significado contido neste som. Consequentemente, a voz é mero meio, é algo que serve a um fim outro, pois seu papel é meramente vocalizar o conceito, torná-lo visível ao olho do espírito de outra pessoa. Tradicionalmente, portanto, a voz é mero resíduo que se exaure depois de cumprir seu destino.

Diante disto, diz Cavarero, a tradução comum do zoon logon echon por "animal racional" se revela um erro bastante perspicaz, pois cristaliza a consideração tácita de que o

${ }^{13}$ CAVARERO, Vozes plurais, p. 22. 
elemento fundador no logos não é o vocal, mas o nexo da palavra com o regime dos significados. Ou seja, apesar de logos também ser voz, som, phoné, na cultura logocêntrica surgida a partir de Platão e Aristóteles (e contra Homero), o decisivo é realmente o conteúdo, o sentido, semantiké, aquilo que pode ser expresso de modo indistinto por absolutamente qualquer voz (ou pela voz de qualquer indivíduo, para usar vocabulário moderno). Para o "animal racional", importa pouco o meio, que se tornará resíduo, pois o essencial está no significado. Não surpreende, portanto, que o ideal do filósofo esteja em ver, não ouvir, as formas ideais e os conceitos, pois a voz perturba a contemplação muda a que só o filósofo tem acesso. É por conta desta possível perturbação que Platão expulsa de sua cidade ideal os poetas, ou seja, o aedos e sua voz prazerosa e enganadora.

Como indiquei acima, a voz analisada por Cavarero é um fenômeno intrinsecamente corporal. A voz é, no fundo, consequência da respiração, do movimento de ar no interior de nosso corpo profundo e que sai de nossa boca úmida e vermelha por meio de vibrações sonoras impalpáveis que penetram, pelo ouvido, as cavidades profundas de outras pessoas. Este fenômeno corporal, é fácil notar, estabelece uma relação direta entre pessoas que partilham um mesmo espaço. Para relacionar as pessoas, a voz como phoné não precisa passar pela semantiké, como prova a experiência simples de ouvir alguém falando uma língua que não conhecemos ou cantando uma melodia, ou também quando estamos diante de um bebê que ainda não domina o código linguístico.

A este fenômeno estritamente corporal, vincula-se um prazer de falar e ouvir; um prazer perceptível já no canto do aedos contra o qual Platão se insurge, perceptível também no prazer pré-edipiano que mistura a sucção do leite à voz da mãe e ao ritmo de seu corpo; um prazer que é amplificado quando fechamos os olhos para ouvir melhor determinado som.

Um dos traços essenciais da tradição, segundo Cavarero, é o silenciamento do logos em benefício da contemplação muda das formas ideais por meio da visão. Este silenciamento foi realizado por Platão e marcou toda a filosofia a partir dele, do que decorreu o desprezo tácito ou explícito da phoné. Com a valorização da semantiké em detrimento da phoné, a tradição se formou criando uma ordem binária que opunha, de um lado, um logos sem voz, ao qual se vincula a filosofia, a razão, o universal, a verdade; e, do outro lado, o falatório, a política, o corpo, o particular, o falso.

A partir desta avaliação da tradição ocidental, as preocupações feministas de Cavarero a conduzem à percepção de que, nesta ordem binária, a dualidade de gêneros encontrada na espécie humana teve um papel determinante. Assim formado, o logos mudo que está na origem de nossa tradição vinculou ao gênero masculino aquilo que o constituía e, inversamente, ao gênero feminino tudo aquilo a que se opunha. São masculinos a semantiké e seus congêneres - filosofia, razão, verdade, luz, ideias; são femininos a phoné e seus congêneres - arte, sentimentos, engano, falsidade, sombras, corpo.

Para explicitar seu argumento, Cavarero traz ao longo de Vozes plurais uma galeria de figuras femininas decisivas para a constituição tradicional da ideia de feminino. Um dos traços marcantes destas figuras é a relação difícil com a semantiké e fácil demais com a phoné. As musas inspiram o poeta, mas quem fala é ele; as sereias cantam para seduzir Ulisses e matá-lo; depois do encontro trágico com Narciso, a ninfa Eco perde seu corpo e se reduz à repetição atrasada e imprecisa do que ouve. $\mathrm{Na}$ época burguesa, a italiana Cavarero vê o 
feminino de modo expressivo no "estranho mundo da ópera", ${ }^{14}$ mundo em que enredos um tanto ridículos produzem prazer incomensurável por meio da voz. Na ópera, Violeta, Tosca, Butterfly e Carmen são figuras um tanto marginais - uma cortesã, uma cantora, uma exótica e uma cigana - que ganham o protagonismo e seduzem a plateia com um canto (phoné) cujo conteúdo (semantikề) é a morte delas mesmas. "Mulheres que vivem à margem dos papéis familiares, figuras transgressivas e, via de regra, independentes, elas não se limitam a morrer, mas devem morrer para que tudo retorne ao seu lugar" ${ }^{\prime 2}$.

Representadas ao longo da tradição como essencialmente fônicas e corporais, sereias, musas, ninfas, cantoras e mães são concebidas como fontes de inspiração e prazer. Distanciadas da semantiké, a inspiração e o prazer por elas incitados vêm do corpo e da voz, o que faz delas a encarnação dos mais terríveis perigos à sabedoria patriarcal. A ordem simbólica patriarcal nunca negou que todos os humanos têm voz, mas considerou sempre que isto vale mais para as mulheres, representadas como essencialmente tagarelas, ou seja, como phoné sem semantiké, do que decorre a necessidade de domá-las, de forçá-las à mudez, como se faz com os animais. Esta proteção da ordem é levada a cabo por meio da filosofia, da razão, do espírito, do silenciamento das vozes.

\section{The Future is Female!}

Ao fim da análise realizada por Cavarero, vemos com clareza que uma das origens das representações tradicionais de homens e mulheres está em um dos termos mais elementares da civilização ocidental; logos. Isto não a conduz, é bom que se diga, à tolice de cancelar Platão ou renegar Aristóteles por eles serem "a fonte" do patriarcado. Cavarero é crítica, não tola, e sua crítica nos revela uma das origens inadvertidas das representações que sustentaram o patriarcado. Uma vez revelado, este aspecto da cultura deve ser desmontado com cuidado, a fim de que ele não se estenda pelo futuro, a fim de que as possibilidades por ele impedidas sejam liberadas, a fim de que as injustiças por ele justificadas sejam corrigidas.

Diante do quadro que revela a distinção entre homens e mulheres a partir da diferença entre phoné e semantiké, surge inicialmente a ideia de que uma política feminista seria aquela que incluísse as mulheres no âmbito da semantiké, ou seja, que permitisse às mulheres o acesso aos papéis masculinos. Deste ponto de vista, mulheres poderosas como Margareth Thatcher ou Dilma Rousseff seriam ícones feministas capazes de inspirar feminismo à direita ou à "esquerda". Não se pode negar a importância de figuras como estas, e arrisco dizer que Cavarero não negaria, mas tal ideia seria ainda pouco diante das ambições da autora, que pretende algo mais ousado.

A proposta política de Cavarero não é a de inverter a representação tradicional, e tampouco dissolvê-las uma na outra, pois seu interesse é combater o silenciamento da voz. "Não se trata de femininizar a política e muito menos de fazê-la coincidir com a pura voz insistindo na potência eversiva do prazer, mas sim de reconduzir a palavra à sua raiz vocálica, subtraindo-lhe ao jogo perverso da economia binária que, cindindo vocálico e semântico, destina-os aos dois gêneros da espécie humana." ${ }^{\prime 16}$

\footnotetext{
${ }^{14}$ CAVARERO, Vozes plurais, p. 146.

${ }^{15}$ CAVARERO, Vozes plurais, p. 152.

${ }^{16}$ CAVARERO, Vozes plurais, p. 240.
} 
Trata-se, portanto, de dar à voz seu lugar de direito na política, de desfazer a cisão entre o vocálico e o semântico, de recusar a superioridade do significado e valorizar o aparecer de alguém por meio de sua voz. A inspiração arendtiana é evidente neste ponto.

Na voz, que é sempre a vOz de alguém, na voz essencialmente destinada à palavra e nela ressoante segundo as leis musicais e relacionadas do eco, não é a mulher que se faz ouvir, mas sim a unicidade encarnada de quem fala e a convocação, por esse alguém, de outra voz. A validade antipatriarcal do vocálico comparece já nesse simples reconhecimento que força a politicidade a desviar-se da palavra para a unicidade corpórea e material dos falantes, bem como para a sua recíproca invocação. Apenas prescindindo-se da pluralidade sonora das vozes, pode-se imaginar, de fato, uma política da palavra que continua a conjugar-se com sujeitos gerais como homem e indivíduo. $\mathrm{O}$ vocálico ataca principalmente pelo lado da ontologia a relação tradicional entre política e palavra. ${ }^{17}$

A política da voz defendida por Cavarero é feminista porque a recondução da palavra à raiz vocálica é algo profundamente antipatriarcal. Ela contraria um dos arranjos fundamentais da ordem simbólica patriarcal porque inclui a unicidade no pensar político.

Sob certa perspectiva, esta maneira de formular a questão é fundamentalmente a mesma maneira pela qual Arendt formula seu conceito de ação. Animada pela preocupação de incluir a singularidade no pensar político, Arendt concebe a ação como uma atividade capaz de revelar quem age. Este quem que o agente revela na ação - e apenas nela - é inteiramente irrepetível, bem como a voz que expressa a unicidade de que fala Cavarero.

A política da voz é, portanto, uma política da performance, uma política da ação que inclui o prazer e a corporeidade de dizer. Vir a público e se relacionar com os demais por meio do dizer, por meio desta atividade que estabelece uma relação com o outro por meio da conexão entre boca e ouvido. Nota bene, uma política do dizer é radicalmente diferente de uma política do dito, ou seja, de uma política que cristaliza o conteúdo veiculado pelo dizer e, desprezando a voz e a singularidade de quem disse, reduzindo o agente a um indivíduo ou a uma classe, analisa o significado contido na mensagem entregue. Dizer é aparecer, com o corpo, ${ }^{18}$ com a voz e a unicidade irrepetíveis, em momento irrepetível, e fazer-se ouvir. O patriarcado lutou por séculos contra isto, e é precisamente por esta razão que devemos fazêlo.

\footnotetext{
${ }^{17}$ CAVARERO, Vozes plurais, p. 240.

${ }^{18}$ Há aqui uma diferença notável entre Arendt e Cavarero. A noção de corpo em Arendt está muito mais vinculada à identidade do que à singularidade, pois, para ela, corpo é a parte em que todos os humanos são fundamentalmente semelhantes, necessitando basicamente das mesmas coisas para mantê-lo (três refeições por dia, abrigo do frio, antibióticos etc.). É graças a esta semelhança que se faz possível a medicina, por exemplo, pois é graças a ela que a aspirina tem efeitos semelhantes em quase todos nós. A aparência exterior do corpo de cada um é parte da singularidade, mas o corpo tomado como entidade biológica, muito felizmente, é fundamentalmente idêntico para todos. Para Cavarero, ao contrário, o corpo produz a voz e, neste sentido, é parte da unicidade, da singularidade. A voz surge de cavidades que não têm aparência política e entra em cavidades auditivas que não também não aparecem, mas Cavarero vincula estreitamente este não aparecer à voz. “O jogo entre emissão vocálica e percepção acústica envolve necessariamente os órgãos internos: implica a correspondência de cavidades carnosas que aludem ao corpo profundo, o mais corpóreo dos corpos. A impalpabilidade das vibrações sonoras, mesmo incolores como o ar, sai da boca úmida e irrompe do vermelho da carne". (CAVARERO, Vozes plurais, p.18)
} 


\section{Referências bibliográficas}

ARENDT, H. The Human Condition. The Chicago University Press, 1998

Between Past and Future. New York: Penguim, 2006

CALVINO, I. "Um rei à escuta”. In. Sob o sol-jaguar. São Paulo: Cia das Letras, 1995

CAVARERO, D. Vozes plurais: filosofia da expressão vocal. Belo Horizonte: Editora UFMG, 2011.

CAVARERO, Adriana; BUTLER, Judith. "Condição humana contra 'natureza". In: Revista Estudos Feministas, Florianópolis, v. 15, n. 3, p. 650, set. 2007.

DIAS, T. Totalitarismo, tempo e ação: uma leitura de A condição humana de Hannah Arendt. 2008. Tese (Doutorado) - Faculdade de Filosofia, Letras e Ciências Humanas. Departamento de Filosofia, Universidade de São Paulo, São Paulo, 2018.

"Hannah Arendt contra a differentia specifica". In. Kriterion (UFMG) 2018, vol.59, n.141, pp. 921-941.

HONIG, B. "Introduction: The Arendt Question in Feminism". In. Feminist Interpretations of Hannah Arendt. HONIG, B (org.). The Pensilvania State University, 1995, pp. 1-16.

MENDES, G. "Diótima e a construção da legitimidade do pensamento da diferença sexual no espaço público”. In: Sísifo. Feira de Santana-BA, n. ${ }^{\circ}$ 6, v. 1, 2017. 